\title{
Fixed point theorems for multivalued maps in cone metric spaces
}

\author{
Seong-Hoon $\mathrm{Cho}^{1^{*}}$ and Jong-Sook Bae ${ }^{2}$
}

\footnotetext{
* Correspondence: shcho@hanseo. ac.kr

${ }^{1}$ Department of Mathematics, Hanseo University, Chungnam 356706, South Korea

Full list of author information is available at the end of the article
}

\author{
Abstract \\ The aim of this article is to generalize a result which is obtained by Mizoguchi and \\ Takahashi [J. Math. Anal. Appl. 141, 177-188 (1989)] to the case of cone metric \\ spaces. \\ MSC: 47H10; 54H25. \\ Keywords: fixed point, multivalued map, cone metric space
}

\section{Introduction}

Banach contraction principle is widely recognized as the source of metric fixed point theory. Also, this principle plays an important role in several branches of mathematics. For instance, it has been used to study the existence of solutions for nonlinear equations, systems of linear equations and linear integral equations and to prove the convergence of algorithms in computational mathematics.

Because of its importance for mathematical theory, Banach contraction principle has been extended in many direction (see [1-8]). Especially, the generalizations to multivalued case are immense too (see $[6,9,10])$.

Mizoguchi and Takahashi proved the following theorem in [9].

Theorem 1.1. Let $(X, d)$ be a complete metric space and let $T: X \rightarrow 2^{X}$ be a multivalued map such that $T x$ is a closed bounded subset of $X$ for all $x L X$. If there exists a function $\phi:(0, \infty) \rightarrow[0,1)$ such that

$$
\lim \sup _{r \rightarrow t^{+}} \varphi(r)<1 \text { for all } t \in[0, \infty)
$$

and if

$$
H(T x, T y) \leq \varphi(d(x, y)) d(x, y)
$$

for all $x, y \in X(x \neq y)$, then $T$ has a fixed point in $X$.

Recently, in [10], the authors introduced a cone metric space which is a generalization of a metric space. They generalized Banach contraction principle for cone metric spaces. Since then, in [11-23], the authors obtained fixed point theorems in cone metric spaces. And the authors [24,25] obtained fixed point results in cone Banach spaces.

The authors [26-28] proved fixed point theorems for multivalued maps in cone metric spaces.

\section{空


In this article, we extend the Hausdorff distance to cone metric spaces, and generalize Theorem 1.1 to the case of cone metric spaces.

Consistent with Huang and Zhang [17], the following definitions will be needed in the sequel.

Let $E$ be a real Banach space. A subset $P$ of $E$ is a cone if the following conditions are satisfied:

(1) $P$ is nonempty closed and $P \neq\{\theta\}$,

(2) $a x+b y \in P$, whenever $x, y \in P$ and $a, b \in \mathbb{R}(a, b \geq 0)$,

(3) $P \cap(-P)=\{\theta\}$.

Given a cone $P \subset E$, we define a partial ordering $\leq$ with respect to $P$ by $x \leq y$ if and only if $y-x \in P$. We write $x<y$ to indicate that $x \leq y$ but $x \neq y$.

For $x, y \in P, x \ll y$ stand for $y-x \in \operatorname{int}(P)$, where $\operatorname{int}(P)$ is the interior of $P$. A cone $P$ is called normal if there exists a number $K>1$ such that for all $x, y \in E,\|x\| \leq K \|$ $y \|$ whenever $\theta \leq x \leq y$.

A cone $P$ is called regular if every increasing sequence which is bounded from above is convergent. That is, if $\left\{u_{n}\right\}$ is a sequence such that for some $z \in E$

$$
u_{1} \leq u_{2} \leq \cdots \leq z
$$

then there exists $u \in E$ such that

$$
\lim _{x \rightarrow \infty}\left\|u_{n}-u\right\|=0 .
$$

Equivalently, a cone $P$ is regular if and only if every decreasing sequence which is bounded from below is convergent.

It has been mentioned [17] that every regular cone is normal (see also [22]).

From now on, we assume that $E$ is a Banach space, $P$ is a cone in $E$ with $\operatorname{int}(P) \neq \emptyset$ and $\leq$ is a partial ordering with respect to $P$.

Let $X$ be a nonempty set. A mapping $d: X \times X \rightarrow E$ is called cone metric [17] on $X$ if the following conditions are satisfied:

(1) $\theta \leq d(x, y)$ for all $x, y \in X$ and $d(x, y)=\theta$ if and only if $x=y$,

(2) $d(x, y)=d(y, x)$ for all $x, y \in X$,

(3) $d(x, y) \leq d(x, z)+d(z, y)$ for all $x, y, z \in X$.

A sequence $\left\{x_{n}\right\}$ in a cone metric space $(X, d)$ converges [17] to a point $x \in X$ (denoted by $\lim _{n \rightarrow \infty} x_{n}=x$ or $x_{n} \rightarrow x$ ) if for any $c \in \operatorname{int}(P)$, there exists $N$ such that for all $n>N, d\left(x_{n}, x\right) \ll c$. A sequence $\left\{x_{n}\right\}$ in a cone metric space $(X, d)$ is Cauchy [17] if for any $c \in \operatorname{int}(P)$, there exists $N$ such that for all $n, m>N, d\left(x_{n}, x_{m}\right) \ll c$. A cone metric space $(X, d)$ is called complete [17] if every Cauchy sequence is convergent.

Lemma 1.1. [17] Let $(X, d)$ be a cone metric space and $P$ be a normal cone, and let $\left\{x_{n}\right\}$ be a sequence in $X$ and $x, y \in X$. Then, we have that

(1) $\lim _{n \rightarrow \infty} x_{n}=x$ if and only if $\lim _{n \rightarrow \infty} d\left(x_{n}, x\right)=\theta$,

(2) $\left\{x_{n}\right\}$ is Cauchy if and only if $\lim _{n}, m \rightarrow \infty d\left(x_{n}, x_{m}\right)=\theta$,

(3) if $\lim _{n \rightarrow \infty} x_{n}=x$ and $\lim _{n \rightarrow \infty} x_{n}=y$, then $x=y$.

We denote by $N(X)$ (resp. $B(X), C B(X))$ the set of nonempty(resp. bounded, sequentially closed and bounded) subset of a metric space or a cone metric space.

Let $(X, d)$ be a cone metric space.

From now on, we denote $s(p)=\{q \in E: p \leq q\}$ for $p \in E$, and $s(a, B)=\mathrm{U}_{b \in B} s(d(a$, b)) for $a \in X$ and $B \in N(X)$. 
For $A, B \in B(X)$, we denote

$$
s(A, B)=\left(\cap_{a \in A} s(a, B)\right) \bigcap\left(\cap_{b \in B} s(b, A)\right) .
$$

Lemma 1.2. Let $(X, d)$ be a cone metric space, and let $P$ be a cone in Banach space E.

(1) Let $p, q \in$ E. If $p \leq q$, then $s(q) \subset s(p)$.

(2) Let $x \in X$ and $A \in N(X)$. If $\theta\lfloor s(x, A)$, then $x \in A$.

(3) Let $q \in P$ and let $A, B \in B(X)$ and $a \in A$. If $q \in s(A, B)$, then $q \in s(a, B)$.

Remark 1.1. Let $(X, d)$ be a cone metric space. If $E=\mathbb{R}$ and $P=[0, \infty)$, then $(X, d)$ is a metric space. Moreover, for $A, B \in C B(X), H(A, B)=\inf s(A, B)$ is the Hausforff distance induced by $d$.

Remark 1.2. Let $(X, d)$ be a cone metric space. Then, $s(\{a\},\{b\})=s(d(a, b))$ for $a, b \in$ $X$.

Lemma 1.3. If $u_{n} \in E$ with $u_{n} \rightarrow \theta$, then for each $c \in \operatorname{int}(P)$ there exists $N$ such that $u_{n} \ll c$ for all $n>N$.

Proof. Let $c \in \operatorname{int}(P)$. There exists $\epsilon>0$ such that

$$
\|c-a\|<\varepsilon \quad \text { implies } a \in \operatorname{int}(P) .
$$

Since $\left\|u_{n}\right\| \rightarrow 0$, there exists $N$ such that $\left\|u_{n}\right\|<\epsilon$ for all $n>N$. Thus, we have $\| c$ $\left(c-u_{n}\right) \|<\epsilon$ and so $c-u_{n} \in \operatorname{int}(P)$ for all $n>N$. Therefore, $u_{n} \ll c$ for all $n>N$.

\section{Fixed point theorems}

Theorem 2.1. Let $(X, d)$ be a complete cone metric space with normal cone $P$ and let $T$ : $X \rightarrow C B(X)$ be a multivalued map. If there exists a function $\phi: P \rightarrow[0,1)$ such that

$$
\lim \sup _{n \rightarrow \infty} \varphi\left(r_{n}\right)<1
$$

for any decreasing sequence $\left\{r_{n}\right\}$ in $P$, and if

$$
\varphi(d(x, y)) d(x, y) \in s(T x, T y)
$$

for all $x, y \in X(x \neq y)$, then $T$ has a fixed point in $X$.

Proof. Let $x_{0} \in X$ and $x_{1} \in T x_{0}$. From (2.1.2), we have

$$
\varphi\left(d\left(x_{0}, x_{1}\right)\right) d\left(x_{0}, x_{1}\right) \in s\left(T x_{0}, T x_{1}\right) .
$$

Thus, we have by Lemma $1.2(3), \phi\left(d\left(x_{0}, x_{1}\right)\right) d\left(x_{0}, x_{1}\right) \in s\left(x_{1}, T x_{1}\right)$.

By definition, we can take $x_{2} \in T x_{1}$ such that $\phi\left(d\left(x_{0}, x_{1}\right)\right) d\left(x_{0}, x_{1}\right) \in s\left(d\left(x_{1}, x_{2}\right)\right)$. So, $d\left(x_{1}, x_{2}\right) \leq \phi\left(d\left(x_{0}, x_{1}\right)\right) d\left(x_{0}, x_{1}\right)$.

Again, we have by (2.1.2), $\phi\left(d\left(x_{1}, x_{2}\right)\right) d\left(x_{1}, x_{2}\right) \in s\left(T x_{1}, T x_{2}\right)$. Thus, we have $\phi\left(d\left(x_{1}\right.\right.$, $\left.x_{2}\right) d\left(x_{1}, x_{2}\right) \in s\left(x_{2}, T x_{2}\right)$.

Thus, we can choose $x_{3} \in T x_{2}$ such that $\phi\left(d\left(x_{1}, x_{2}\right)\right) d\left(x_{1}, x_{2}\right) \in s\left(d\left(x_{2}, x_{3}\right)\right)$ and so $d$ $\left(x_{2}, x_{3}\right) \leq \phi\left(d\left(x_{1}, x_{2}\right)\right) d\left(x_{1}, x_{2}\right)$.

Inductively, we can construct a sequence $\left\{x_{n}\right\}$ in $X$ such that for $n=1,2, \ldots$,

$$
d\left(x_{n}, x_{n+1}\right) \leq \varphi\left(d\left(x_{n-1}, x_{n}\right)\right) d\left(x_{n-1}, x_{n}\right), \quad x_{n+1} \in T x_{n} .
$$

If $x_{n}=x_{n+1}$ for some $n \in \mathbb{N}$, then $T$ has a fixed point. 
We may assume that $x_{n} \neq x_{n+1}$ for all $n \in \mathbb{N}$. From (2.1.3), $\left\{d\left(x_{n}, x_{n+1}\right)\right\}$ is a decreasing sequence in $P$. From (2.1.1), there exists $r \in(0,1)$ such that

$$
\lim \sup _{n \rightarrow \infty} \varphi\left(d\left(x_{n}, x_{n+1}\right)\right)=r .
$$

Thus, for any $l \in(r, 1)$, there exists $n_{0} \in \mathbb{N}$ such that for all $n \geq n_{0}, \phi\left(d\left(x_{n-1}, x_{n}\right)\right)<l$. Without loss of generality, we may assume $n_{0}=1$. Then, we have

$$
d\left(x_{n}, x_{n+1}\right) \leq \varphi\left(d\left(x_{n-1}, x_{n}\right)\right) d\left(x_{n-1}, x_{n}\right)<l d\left(x_{n-1}, x_{n}\right)<l^{n} d\left(x_{0}, x_{1}\right) .
$$

For $m>n$, we have

$$
d\left(x_{n}, x_{m}\right) \leq \frac{l^{n}}{1-l} d\left(x_{0}, x_{1}\right) .
$$

By Lemma 1.3, $\left\{x_{n}\right\}$ is a Cauchy sequence in $X$. It follows from the completeness of $X$ that there exists $u \in X$ such that $\lim _{n \rightarrow \infty} x_{n}=u$.

We now show that $u \in T u$.

From (2.1.2), we have $\phi\left(d\left(x_{n}, u\right)\right) d\left(x_{n}, u\right) \in s\left(T x_{n}, T u\right)$ for $n \in \mathbb{N}$. By Lemma 1.2 (3), we obtain

$$
\varphi\left(d\left(x_{n}, u\right)\right) d\left(x_{n}, u\right) \in s\left(x_{n+1}, T u\right) .
$$

Thus, there exists $v_{n} \in T u$ such that

$$
\varphi\left(d\left(x_{n}, u\right)\right) d\left(x_{n}, u\right) \in s\left(d\left(x_{n+1}, v_{n}\right)\right) .
$$

Hence, $d\left(x_{n+1}, v_{n}\right) \leq d\left(x_{n}, u\right)$. Thus, we have

$$
d\left(u, v_{n}\right) \leq d\left(u, x_{n+1}\right)+d\left(x_{n+1}, v_{n}\right) \leq d\left(u, x_{n+1}\right)+d\left(x_{n}, u\right) .
$$

By letting $n \rightarrow \infty$ in above inequality and by Lemma 1.1, we have $\lim _{n \rightarrow \infty} d\left(u, v_{n}\right)=$ 0 . Again, by Lemma 1.1, $\lim _{n \rightarrow \infty} v_{n}=u$. Since $T u$ is closed, $u \in T u$.

Remark 2.1. (1) By Remark 1.1, Theorem 2.1 generalize Theorem 1.1 [Theorem 5, 13].

(2) The authors $[26,28]$ obtained fixed point theorems for multivalued maps $T$ defined on cone metric spaces $(X, d)$ under assumption that the function $I(x)=\inf _{x \in T x} \| d(x$, $y) \|$ is lower semicontinuous, and the author [27]obtained a fixed point theorem for multivalued maps $T$ under assumptions that the function $I(x), x \in X$ is lower semicontinuous and a dynamic process is given.

(3) In [26-28], the authors do not use the concept of the Hausdorff metric on cone metric spaces, and their results cannot be applied directly to obtain the following corollaries 2.2-2.5.

Collorary 2.2. Let $(X, d)$ be a complete cone metric space with normal cone $P$ and let $T: X \rightarrow C B(X)$ be a multivalued map. If there exists a monotone increasing function $\phi:$ $P \rightarrow[0,1)$ such that

$$
\varphi(d(x, y)) d(x, y) \in s(T x, T y)
$$

for all $x, y \in X(x \neq y)$, then $T$ has a fixed point in $X$.

The following result is Nadler multivalued contraction fixed point theorem in cone metric space. 
Collorary 2.3. Let $(X, d)$ be a complete cone metric space with normal cone $P$ and let $T: X \rightarrow C B(X)$ be a multivalued map. If there exists a constant $k \in[0,1)$ such that

$$
k d(x, y) \in s(T x, T y)
$$

for all $x, y \in X$, then $T$ has a fixed point in $X$.

By Remark 1.1, we have the following corollaries.

Collorary 2.4. [29] Let $(X, d)$ be a complete metric space and let $T: X \rightarrow C B(X)$ be a multivalued map. If there exists a monotone increasing function $\phi:(0, \infty) \rightarrow[0,1)$ such that

$$
H(T x, T y) \leq \varphi(d(x, y)) d(x, y)
$$

for all $x, y \in X(x \neq y)$, then $T$ has a fixed point in $X$.

Collorary 2.5. [6] Let $(X, d)$ be a complete metric space and let $T: X \rightarrow C B(X)$ be a multivalued map. If there exists a constant $k \in[0,1)$ such that

$$
H(T x, T y) \leq k d(x, y)
$$

for all $x, y \in X$, then $T$ has a fixed point in $X$.

The following example illustrates our main theorem.

Example 2.1. Let $X=L^{1}[0,1], E=C[0,1]$ and $P=\{f \in E: f \geq 0\}$. Then, $P$ is a normal cone with normal constant $K=1$. Define $d: X \times X \rightarrow E$ by $d(f, g)(t)=\int_{0}^{t}|f(x)-g(x)| d x$, where $0 \leq t \leq 1$. Then, $d$ is a cone metric on $X$. Consider a mapping $T: X \rightarrow C B(X)$ defined by

$$
(T f)(x)=\int_{0}^{x} y(f(y)-1) d y .
$$

Let $\varphi(t)=\frac{1}{2}$ for all $t \in P$. Obviously, condition (2.1.1) is satisfied.

We show that condition (2.1.2) is satisfied.

Consider the following inequality.

$$
\begin{aligned}
& d(T f, T g)(t) \\
= & \int_{0}^{t}\left|\int_{0}^{x} \gamma(f(y)-1) d y-\int_{0}^{x} \gamma(g(y)-1) d y\right| d x \\
= & \int_{0}^{t}\left|\int_{0}^{x} \gamma(f(y)-g(y)) d y\right| d x \\
\leq & \int_{0}^{t} \int_{0}^{x} \gamma|f(y)-g(y)| d y d x \\
= & \int_{0}^{t} \int_{y}^{t} \gamma|f(y)-g(y)| d x d y \\
= & \int_{0}^{t}(t-y) y|f(y)-g(y)| d y \\
\leq & \int_{0}^{t} \frac{t^{2}}{4}|f(y)-g(y)| d y \\
\leq & \frac{1}{4} \int_{0}^{t}|f(y)-g(y)| d y \\
= & \frac{1}{4} d(f, g)(t) .
\end{aligned}
$$

Thus, we have $\frac{1}{4} d(f, g) \in s(d(T f, T g))=s(T f, T g)$. Hence, $\varphi(d(f, g)) d(f, g)=\frac{1}{2} d(f, g) \in s(T f, T g)$. 
Therefore, all conditions of Theorem 2.1 are satisfied and $T$ has a fixed point $f *(x)=-e^{\frac{x^{2}}{2}}+1$

\section{Acknowledgements}

This research was supported by the Basic Science Research Program through the National Research Foundation of Korea (NRF) funded by the Ministry of Education, Science and Technology (No. 2011-0012118). The authors express their gratitude to the referees for useful remarks and suggestions.

\section{Author details}

'Department of Mathematics, Hanseo University, Chungnam 356-706, South Korea ${ }^{2}$ Department of Mathematics, Moyngji University, Yongin 449-728, South Korea

\section{Authors' contributions}

All authors contributed equally and significantly in writing this article. All authors read and approved the final manuscript.

\section{Competing interests}

The authors declare that they have no competing interests.

\section{Received: 9 July 2011 Accepted: 25 November 2011 Published: 25 November 2011}

\section{References}

1. Agarawl, RP, O'Regan, DO, Shahzad, N: Fixed point theorems for generalized contractive maps of Mei-Keeler type. Math. Nachr. 276, 3-12 (2004). doi:10.1002/mana.200310208

2. Aubin, JP, Siegel, J: Fixed point and stationary points of dissipative multi-valued maps. Proc Amer Math Soc. $\mathbf{7 8}$ 391-398 (1980). doi:10.1090/50002-9939-1980-0553382-1

3. Branciari, A: A fixed point theorem for mappings satisfying a general contractive condition of integral type. Int J Math Math Sci. 29, 531-536 (2002). doi:10.1155/S0161171202007524

4. Covitz, H, Nadler, SB Jr: Multi-valued contraction mappings in generalized metric spaces. Israel J Math. 8, 5-11 (1970). doi:10.1007/BF02771543

5. Feng, Y, Liu, S: Fixed point theorems for multi-valued contractive mappings and multi-valued Caristi type mappings. J Math Anal Appl. 317, 103-112 (2006). doi:10.1016/i.jmaa.2005.12.004

6. Nadler, SB Jr: Multi-valued contraction mappings. Pacific J Math. 30, 475-478 (1969)

7. Vijayaraju, $\mathrm{P}, \mathrm{Rhoades}, \mathrm{BE}$, Mohanraj, R: A fixed point theorem for a pair of maps satisfying a general contractive condition of integral type. Int J Math Math Sci. 15, 2359-2364 (2005)

8. Wang, T: Fixed point theorems and fixed point stability for multivalued mappings on metric spaces. J Nanjing Univ Math Baq. 6, 16-23 (1989)

9. Mizoguchi, N, Takahashi, W: Fixed point theorems for multi-valued mappings on complete metric spaces. J Math Anal Appl. 141, 177-188 (1989). doi:10.1016/0022-247X(89)90214-X

10. Reich, S: Some problems and results in fixed point theory. Contemp Math. 21, 179-187 (1983)

11. Alnafei, SH, Radenović, S, Shahzad, N: Fixed point theorems for mappings with convex diminishing diameters on cone metric spaces. Appl Math Lett. 24, 2162-2166 (2011). doi:10.1016/j.aml.2011.06.019

12. Abbas, M, Jungck, G: Common fixed point results for noncommuting mappings without continuity in cone metric spaces. J Math Anal Appl. 341, 416-420 (2008). doi:10.1016/j.jmaa.2007.09.070

13. Abbas, M, Rhoades, BE: Fixed and periodic point results in cone metric spaces. Appl Math Lett. (2008)

14. Abdeljawad, T, Karapinar, E: A gap in the paper "A note on cone metric fixed point theory and its equivalence". Gazi Univ J Sci 24(2), 233-234 (2011). [Nonlinear Anal. 72(5), 2259-2261 (2010)]

15. Cho, SH, Bae, JS: Common fixed point theorems for mappings satisfying property (E.A) on cone metric spaces. Math Comput Modelling. 53, 945-951 (2011). doi:10.1016/j.mcm.2010.11.002

16. Choudhury, BS, Metiya, N: Fixed points of weak contractions in cone metric spaces. Nonlinear Anal. (2009)

17. Huang, LG, Zhang, X: Cone metric spaces and fixed point theorems of contractive mappings. J Math Anal Appl. 332(2), 1468-1476 (2007). doi:10.1016/j.jmaa.2005.03.087

18. Ilić, D, Rakočević, V: Common fixed points for nmaps on cone metric spaces. J Math Anal Appl. 341, 876-882 (2008). doi:10.1016/j.jmaa.2007.10.065

19. Ilić, D, Rakočević, V: Quasi-contraction on cone metric spaces. Appl Math Lett. (2008)

20. Karapinar, E: Some nonunique fixed point theorems of Ciric type on cone metric spaces. Abstr Appl Anal 14 (2010). Article ID 123094, (2010)

21. Karapinar, E: Couple fixed point theorems for nonlinear contractions in cone metric spaces. Comput Math Appl. 59(12), 3656-3668 (2010). doi:10.1016/j.camwa.2010.03.062

22. Rezapour, Sh, Hamlbarani, R: Some notes on the paper "Cone metric spaces and fixed point theorems of contractive mappings". J Math Anal Appl. 345, 719-724 (2008). doi:10.1016/j.jmaa.2008.04.049

23. Yang, SK, Bae, JS, Cho, SH: Coincidence and common fixed and periodic point theorems in cone metric spaces. Comput Math Appl. 61, 170-177 (2011). doi:10.1016/j.camwa.2010.10.031

24. Karapinar, E: Fixed point theorems in cone Banach spaces. Fixed Point Theory Appl 9 (2009). 2009, Article ID 609281.

25. Karapinar, E, Trkoglu, DA: Best approximations for a couple in cone Banach spaces. Fixed Point Theory Appl 9 (2010). 2010 Article ID 784578

26. Kadelburg, Z, Radenovič, S: Some results on set-valued contractions in abstract metric spaces. Comput Math Appl. 62 , 342-350 (2011). doi:10.1016/j.camwa.2011.05.015 
27. Klim, D, Wardowski, D: Dynamic processes and fixed points of set-valued nonlinear contractions in cone metric spaces. Nonlinear Anal. 71, 5170-5175 (2009). doi:10.1016/j.na.2009.04.001

28. Wardowski, D: Endpoints and fixed points of set-valued contractions in cone metric spaces. Nonlinear Anal. 71, 512-516 (2009). doi:10.1016/j.na.2008.10.089

29. Daffer, PZ, Kaneko, H: Fixed points of generalized contractive multi-valued mappings. J Math Anal Appl. 192, 655-666 (1995). doi:10.1006/jmaa.1995.1194

doi:10.1186/1687-1812-2011-87

Cite this article as: Cho and Bae: Fixed point theorems for multivalued maps in cone metric spaces. Fixed Point Theory and Applications 2011 2011:87.

Submit your manuscript to a SpringerOpen ${ }^{\circ}$ journal and benefit from:

$\rightarrow$ Convenient online submission

- Rigorous peer review

- Immediate publication on acceptance

- Open access: articles freely available online

- High visibility within the field

- Retaining the copyright to your article

Submit your next manuscript at $\boldsymbol{s p r i n g e r o p e n . c o m ~}$ 